\title{
Psychological interventions for adults with bipolar disorder: systematic review and meta-analysis
}

Matthijs Oud, Evan Mayo-Wilson, Ruth Braidwood, Peter Schulte, Steven H. Jones, Richard Morriss, Ralph Kupka, Pim Cuijpers and Tim Kendall

\section{Background}

Psychological interventions may be beneficial in bipolar disorder.

\author{
Aims \\ To evaluate the efficacy of psychological interventions for \\ adults with bipolar disorder.
}

\section{Method}

A systematic review of randomised controlled trials was conducted. Outcomes were meta-analysed using RevMan and confidence assessed using the GRADE method.

\section{Results}

We included 55 trials with 6010 participants. Moderate-quality evidence associated individual psychological interventions with reduced relapses at post-treatment (risk ratio $(R R)=0.66$, 95\% Cl 0.48-0.92) and follow-up (RR=0.74, 95\% Cl 0.63-0.87), and collaborative care with a reduction in hospital admissions
(RR $=0.68,95 \%$ Cl 0.49-0.94). Low-quality evidence associated group interventions with fewer depression relapses at posttreatment and follow-up, and family psychoeducation with reduced symptoms of depression and mania.

\section{Conclusions}

There is evidence that psychological interventions are effective for people with bipolar disorder. Much of the evidence was of low or very low quality thereby limiting our conclusions. Further research should identify the most effective (and cost-effective) interventions for each phase of this disorder.

\section{Declaration of interest}

R.M. and S.H.J. are authors of three included studies.

\section{Copyright and usage}

(C) The Royal College of Psychiatrists 2016.
Bipolar disorder affects approximately $1.5 \%$ of the population, ${ }^{1-5}$ and often takes a chronic course with recurrent manic, hypomanic, depressive and mixed episodes. Bipolar disorder is associated with poor psychosocial functioning, ${ }^{6}$ a high economic burden, ${ }^{7-10}$ and early mortality. ${ }^{11}$ People with bipolar disorder are symptomatically ill almost half the time. ${ }^{12}$ Although mania often results in hospital admission, ${ }^{13}$ depressive symptoms and episodes account for most illness-related disability. ${ }^{1}$ In trying to manage the illness, people with bipolar disorder use pharmacological interventions, but $60 \%$ of people who commence out-patient maintenance treatment will have an episode within 2 years. ${ }^{13}$ As an additional strategy, many people with bipolar disorder wish to use psychological interventions to improve symptoms and reduce relapse rates. Previous meta-analyses have evaluated evidence for specific psychological interventions such as cognitive-behavioural therapy (CBT) ${ }^{14-18}$ family interventions and psychoeducation, ${ }^{17-19}$ some during acute episodes and some during euthymic periods, with varying durations of intervention and follow-up. The number of relevant trials has tripled since the last meta-analysis and a new comprehensive review is needed to inform the selection of psychological interventions for each stage of bipolar disorder. We therefore conducted a systematic review and meta-analysis of psychological interventions for adults with bipolar disorder compared with control groups (treatment as usual, waiting list, attention control or an active intervention) on symptoms of depression and mania, response, relapse, discontinuation, hospital admission, quality of life and psychosocial functioning. This review informed the guidelines on the management of bipolar disorder issued by the National Institute for Health and Care Excellence (NICE) and The Netherlands Psychiatric Association and Trimbos Institute, ${ }^{20,21}$ and is reported here following the Preferred Reporting Items for Systematic Reviews and Meta-analyses (PRISMA) guidelines. ${ }^{22}$

\section{Method}

We included randomised controlled trials (RCTs) of all individual, group and family psychological interventions for adults (18 years and older). We also included service-level interventions with (elements of) psychological interventions such as collaborative care. Eligible comparison groups were control groups (treatment as usual, waiting list or attention control) or other active interventions. Trials were eligible if at least $66 \%$ of the sample had bipolar disorder or if disaggregated data were reported for participants with the disorder. For trials including people with other mental disorders (e.g. major depressive disorder or schizophrenia) we requested disaggregated data.

\section{Search strategy}

We searched CINAHL, EMBASE, Medline, PreMedline, PsycINFO, CDSR, DARE, HMIC and CENTRAL from inception to January 2014 using terms for bipolar disorder and randomised clinical trials (see online data supplement). Searches were not restricted by language. Authors M.O. and R.B. assessed the eligibility of studies for inclusion and discussed disagreements with a third author (E.M.-W.). We then searched the reference lists of the included studies, excluded studies and previous reviews. We contacted study authors and experts to request additional reports of trials. German language reports were translated by P.S.

\section{Assessment of bias}

Studies were assessed and rated independently by two authors (M.O., P.C.) using the Cochrane Collaboration risk of bias assessment tool. ${ }^{23}$ Disagreements were discussed with a third author (E.M.-W.) and resolved by consensus. Each study was rated 
for risk of bias due to sequence generation; allocation concealment; masking (blinding) of participants, assessors and providers; selective outcome reporting (e.g. reporting incomplete data or not all of the outcomes measured); and incomplete data. Risk of bias for each domain was rated as high (seriously weakens confidence in the results), low (unlikely to seriously alter the results) or unclear.

\section{Data management}

Patient outcomes included reduction of symptoms of depression and mania (response), relapse (any type, depression, mania or mixed), hospital admission, quality of life, suicide, psychosocial functioning and study discontinuation. We also extracted treatment format, number and length of sessions, method of recruitment, inclusion and exclusion criteria, age, gender, setting, study location and number of people with type 1 bipolar disorder. Study characteristics are reported in online Table DS1. Treatment in the acute phase typically aims at remission of the index episode, and if symptoms of the index episode reappear after a short period the term 'relapse' is often used. Long-term management aims to prevent future episodes, often termed 'recurrence.. ${ }^{24}$ In this review it was impossible to distinguish between relapse and recurrence because studies included participants with acute symptoms as well as those who were euthymic without reporting disaggregated data; we have used the term 'relapse' for both outcomes.

\section{Statistical analysis}

Psychological treatments developed for bipolar disorder may differ in the underlying therapeutic tradition (e.g. CBT, interpersonal therapy, psychoeducation) and delivery, but they share nonspecific treatment factors (e.g. contact with a caring professional, problem-solving, coping with stigma), ${ }^{25}$ so their effects may be aggregated in meta-analysis to explore the range of potential effects. In this review, psychotherapies were aggregated by method of delivery, comprising individual treatment, group treatment, family therapy and collaborative care. Information about the effects of interventions with different therapeutic traditions were analysed in subgroups. For continuous outcomes we calculated the standardised mean difference (SMD), Hedges' $g$ for between-group differences. For dichotomous outcomes we calculated the risk ratio (RR) for events. All outcomes are reported with $95 \%$ confidence intervals. Overall effects were calculated using random effects models. Continuous effects were weighted by the inverse of variance; dichotomous effects were weighted using the Mantel-Haenszel method. ${ }^{23}$ Because time-to-event data were reported inconsistently, and often incompletely (e.g. as curves without associated events or statistics), we were unable to analyse these results; however, most studies were short and similar in duration, and hazard ratios would be similar to the relative risks reported here.

Missing data were noted for each outcome. When missing cases were not reported we contacted the authors. If continuous outcomes were reported for those completing the trial as well as controlling for missing data (for example, imputed using regression methods), we used the data that controlled for missing data. Statistical heterogeneity was assessed by visual inspection of forest plots, by $\chi^{2}$-tests (assessing the $P$-value) and by calculating the $I^{2}$ statistic, which describes the percentage of observed heterogeneity that would not be expected by chance. If $P<0.10$ and $I^{2}$ exceeded $50 \%$ we considered heterogeneity to be substantial. Meta-analyses of comparisons and subgroups were conducted using RevMan $5.2{ }^{26}$ owing to the few studies per type of intervention a meta-regression would not be meaningful and was therefore not conducted. Confidence in the results was assessed by M.O. and E.M.-W. using the Grades of
Recommendation, Assessment, Development and Evaluation (GRADE) method, ${ }^{27}$ which is a structured assessment of the quality of evidence attending to the following factors: risk of bias, inconsistency, indirectness, imprecision and publication bias.

\section{Results}

Of 13641 potentially relevant citations and 4 from other sources we retrieved 59 papers, which were assessed for inclusion (Fig. 1). Of these, three were excluded because only a minority of participants had bipolar disorder and we could not obtain disaggregated data, ${ }^{28-30}$ and one was a trial of a measurement instrument. $^{31}$ Fifty-five randomised controlled trials were therefore included: four were unpublished at the time of inclusion, ${ }^{32-35}$ two had been recently published, ${ }^{34,35}$ and fifty-one trials had been published between 1984 and 2014. Seven were not included in the meta-analysis because they did not report usable outcomes, which remained unavailable after we contacted the authors. ${ }^{36-42}$

\section{Study characteristics}

Table DS1 presents study characteristics for each trial. Included studies randomised 6010 participants, ranging from 19 to 441 per study. Studies were conducted in North America $(k=22)$, England and Ireland $(k=12)$, central Europe $(k=11)$, Australia $(k=5)$, Brazil $(k=3)$ and Iran $(k=2)$. Participants were recruited

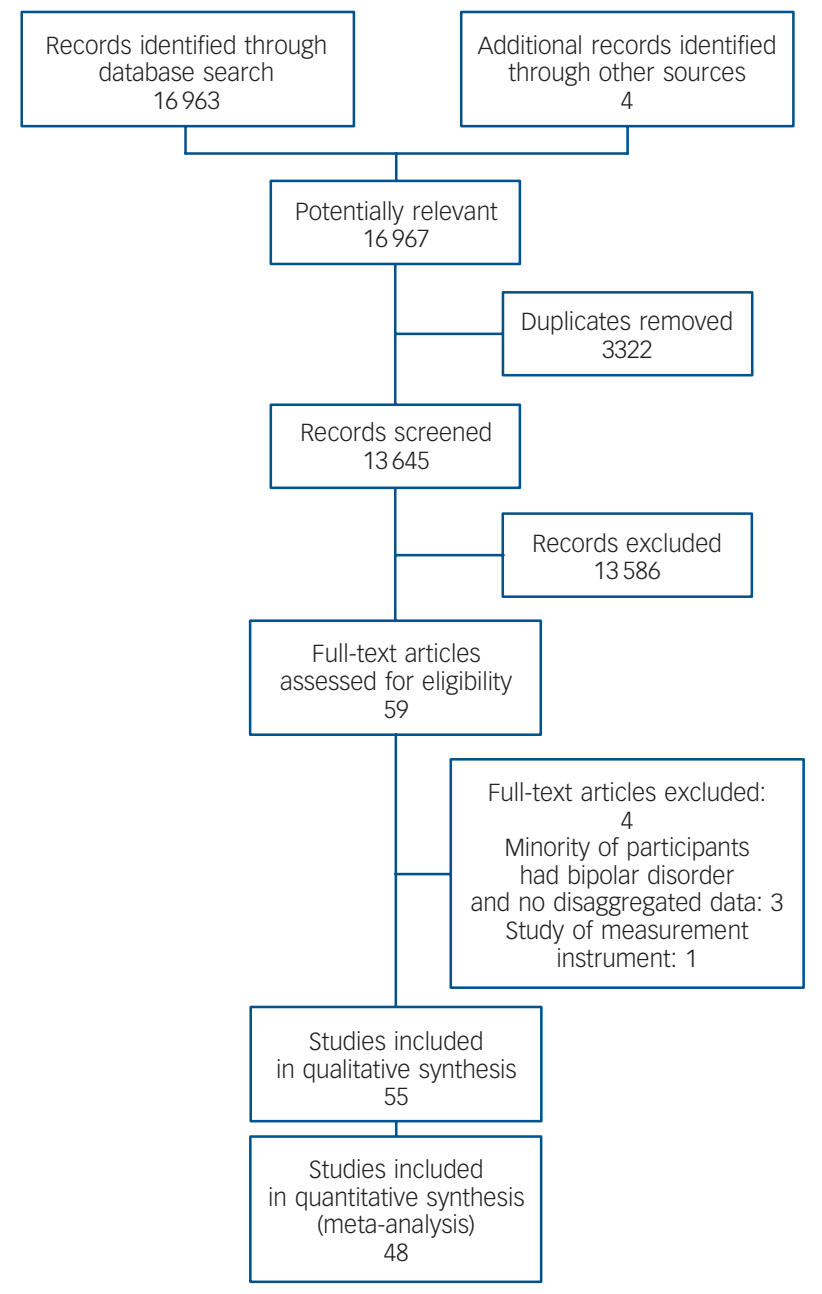

Fig. 1 Study selection. 
from out-patient $(k=23)$ or in-patient settings $(k=12)$, primary care practices $(k=2)$, community mental health teams $(k=2)$ or advertising combined with (self-)referral $(k=16)$. In 52 studies a diagnostic interview was used to establish the presence of bipolar disorder, in one study participants themselves reported whether they had bipolar disorder, another confirmed the diagnosis through a questionnaire, and one study reported only that bipolar disorder was an inclusion criterion. Across all trials the median of the mean ages of participants was 40 years (range 26-55); the median percentage who were female was 58\% (range 9-77) and the median percentage of participants with type 1 bipolar disorder was $81 \%$ (range $42-100$, apart from one study with $0 \%$ ). Four studies included participants experiencing a depressive episode at baseline, ${ }^{43-46}$ six studies included participants experiencing depressive and manic episodes, ${ }^{37,38,47-50}$ and thirty-two studies included only euthymic participants. Twelve studies included a mix of euthymic and symptomatic cases at baseline, ${ }^{35,40,41,51-59}$ of which only two studies provided disaggregated data. ${ }^{35,59}$

\section{Interventions}

Trials included a variety of interventions (online Table DS2) and comparison conditions, and were grouped in nine comparisons. The first five were interventions compared with treatment as usual (individual treatment, group treatment, family therapy, collaborative care, integrated cognitive and interpersonal therapy). Four comparisons included interventions compared with other active interventions (head-to-head trials).

\section{Outcomes}

Online Table DS3 lists the continuous measures used in the trials categorised by outcome type. Dichotomous data were also reported. Response was determined through clinical interviews, such as the Structured Clinical Interview for DSM (SCID); cutoff points on diverse scales, e.g. when scored as symptomatic at baseline and at follow-up scoring below 11 on the Young Mania Rating Scale (YMRS) for mania response or below 6 on the Bech-Rafaelsen Melancholia Scale for depression response; or a percentage of reduction on a scale, e.g. $50 \%$ on the Hamilton Rating Scale for Depression (HRSD) for a depression response. In most trials participants had to score above a cut-off score for a certain time (e.g. 2 months) to be considered responsive. Relapse in most cases was determined with clinical interviews, for example with the SCID, the Schedule for Affective Disorders and Schizophrenia, and the Mini-International Neuropsychiatric Interview. Other trials established relapse in participants with a score above a cut-off point on a depression scale (e.g. above 12 on the HRSD) or a mania scale (e.g. above 20 on the YMRS); in some, a combination of the two scales was used to evaluate the presence of mixed episodes. Five studies assumed that a relapse had occurred based on chart reviews or hospital records.

\section{Risk of bias}

Each risk of bias item is presented as a percentage across all studies in online Fig. DS1 and for each study independently in online Fig. DS2. No trial was at high risk of bias for random sequence generation; however, the method of randomisation was not reported in 15 trials. Allocation concealment was unclear in 25 trials and low risk in 30 trials. Masking of participants and providers in trials of psychological interventions is impossible, so all were at high risk of bias per se. Nine trials used only selfreport measures and 32 trials reported masked assessor-rated outcomes; these 41 trials were at low risk of bias for allocation concealment. However, eight studies did not have masked assessment and these were considered to be at high risk of bias. In six studies it was unclear whether assessors were unaware of assignment. For incomplete outcome data, 25 trials were at low risk of bias and 24 were at high risk of bias because of the number (more than 10\%) of missing cases or because missing cases were excluded from the analyses. In six studies the handling of missing data was not described.

\section{Reporting bias}

Risk of reporting bias could not be assessed indirectly (e.g. using funnel plots or statistical methods) because there were few studies for most comparisons and the studies were of similar size. We used direct methods to assess risk of reporting bias by checking trial registrations and by contacting authors. There was a high risk of reporting bias in 22 trials, including seven studies that did not report any usable data. In addition to the outcomes we analysed, several trials also reported incomplete results that could not be included in the meta-analysis. Only 11 studies were prospectively registered, but 23 others were assessed to be at low risk of bias because authors provided missing data or confirmed that all outcomes were published.

\section{Overall evidence quality}

Using the GRADE method, ${ }^{27}$ many outcomes were downgraded because of risk of bias (e.g. inappropriate handling of missing data). Nearly all results were downgraded at least one level because of imprecision (the analyses included few participants or events). Results for relapse following individual interventions, hospital admission following collaborative care, and study discontinuation during interpersonal and social rhythm therapy (IPSRT) were of moderate quality. Most other evidence was of low or very low quality. Studies also reported controlled comparisons at follow-up, but most outcomes were of very low quality.

\section{Quantitative data synthesis}

Across nine comparisons, results of the meta-analyses suggest that psychological interventions may be associated with symptomatic improvement and with fewer relapses and hospital admissions. The majority of these low- to moderate-quality outcomes are summarised per comparison and presented in Tables 1 and 2 (post-treatment) and Tables 3 and 4 (follow-up) with reasons for downgrading; for all outcomes per comparison and subgroups we refer to online Tables DS4 and DS5.

\section{Individual psychological interventions}

The search identified 15 RCTs $(n=1580)$ of face-to-face and interactive online psychoeducation, ${ }^{35,59-64}$ cognitive therapy or $\mathrm{CBT},{ }^{34,43,51,52,65-68}$ and medication adherence therapy. ${ }^{69}$ Interventions were compared with treatment as usual. Eleven trials enrolled participants who were euthymic at baseline and four trials enrolled a mix of participants experiencing an acute episode of mania or depression and those who were euthymic. ${ }^{35,51,52,59}$ Seven trials $(n=637)$ reported low-quality evidence that individual psychological interventions were associated with a small reduction in symptoms of depression post-treatment. ${ }^{35,51,59,65-68}$ Six trials $(n=365)$ reported moderate-quality evidence that such interventions reduced the risk of relapse post-treatment. ${ }^{51,64-66,68,69}$ However, three trials found no difference in effect on symptoms of mania. ${ }^{65,67,68}$ One trial with few events was inconclusive regarding the risk of hospital admission. ${ }^{69}$ Eight trials $(n=532)$ reported moderate-quality evidence that individual psychological interventions were associated with a reduction in relapse at follow-up. ${ }^{59,63-66,68,69}$ There was low-quality evidence from three trials $(n=214)$ that individual psychological interventions might 


\begin{tabular}{|c|c|c|c|c|c|}
\hline Outcome & $\begin{array}{l}\text { Number of studies }(k) \\
\text { and participants }(n)\end{array}$ & Effect size $(95 \% \mathrm{Cl})$ & $\begin{array}{l}\text { Heterogeneity } \\
\chi^{2}(P), I^{2}\end{array}$ & $\begin{array}{l}\text { Intervention } \\
\text { length, weeks }\end{array}$ & $\begin{array}{l}\text { Quality } \\
\text { (GRADE) }\end{array}$ \\
\hline \multicolumn{6}{|c|}{ Individual psychological intervention } \\
\hline Depression symptoms & $k=8, n=683$ & $\mathrm{SMD}=-0.23(-0.41$ to -0.05$)$ & $8.55(0.29), 18 \%$ & $6-26$ & Low $^{a, b}$ \\
\hline Mania symptoms & $k=3, n=171$ & $\mathrm{SMD}=-0.05(-0.35$ to 0.25$)$ & $0.48(0.79), 0 \%$ & 26 & Very low $w^{a, b, c}$ \\
\hline Hospital admission & $k=1, n=28$ & $R R=0.14(0.01$ to 2.53$)$ & NA & 6 & Low $^{\mathrm{b}, \mathrm{c}}$ \\
\hline Relapse (any) & $k=6, n=365$ & $\mathrm{RR}=0.66(0.48$ to 0.92$)$ & $2.50(0.78), 0 \%$ & $6-26$ & Moderate $^{c}$ \\
\hline Response & $k=1, n=33$ & $\mathrm{RR}=0.71(0.46$ to 1.07$)$ & NA & 26 & very low ${ }^{b, c}$ \\
\hline \multicolumn{6}{|c|}{ Group psychological intervention } \\
\hline Depression symptoms & $k=8, n=423$ & $\mathrm{SMD}=-0.24(-0.64$ to 0.16$)$ & $25.65(<0.001) ; 73 \%$ & $8-52$ & Very low $w^{a, c, d}$ \\
\hline Mania symptoms & $k=6, n=375$ & $\mathrm{SMD}=-0.08(-0.33$ to 0.16$)$ & $5.60(0.35), 11 \%$ & $8-52$ & Very low $w^{a, b, c}$ \\
\hline Hospital admission & $k=3, n=205$ & $R R=0.45$ (0.10 to 2.09) & $3.94(0.14), 49 \%$ & $14-21$ & LOW $^{\mathrm{C}}$ \\
\hline Relapse (any) & $k=2, n=170$ & $\mathrm{RR}=0.48(0.22$ to 1.04$)$ & $2.42(0.12), 59 \%$ & 21 & LOW $^{c}$ \\
\hline Relapse (depression) & $k=2, n=170$ & $\mathrm{RR}=0.39(0.19$ to 0.78$)$ & $0.45(0.50), 0 \%$ & 21 & Low $^{c}$ \\
\hline Relapse (mania) & $k=2, n=170$ & $\mathrm{RR}=0.48(0.28$ to 0.82$)$ & $0.80(0.37), 0 \%$ & 21 & LOW $^{\mathrm{C}}$ \\
\hline \multicolumn{6}{|l|}{ Family psychoeducation } \\
\hline Depression symptoms & $k=1, n=43$ & $\mathrm{SMD}=-0.73(-1.35$ to -0.10$)$ & NA & 14 & LOW $^{\mathrm{b}, \mathrm{c}}$ \\
\hline Mania symptoms & $k=1, n=43$ & $\mathrm{SMD}=-0.66(-1.28$ to -0.04$)$ & NA & 14 & LOW $^{b, c}$ \\
\hline \multicolumn{6}{|l|}{ Collaborative care } \\
\hline Depression symptoms & $k=2, n=123$ & $\mathrm{SMD}=-0.22(-0.63$ to 0.19$)$ & $1.32(0.25), 24 \%$ & $26-30$ & $\operatorname{LOW}^{a, b, c}$ \\
\hline Mania symptoms & $k=2, n=123$ & $\mathrm{SMD}=-0.07(-0.47$ to 0.32$)$ & $1.24(0.27), 19 \%$ & $26-30$ & Low $^{a, b, c}$ \\
\hline Hospital admission & $k=3, n=572$ & $\mathrm{RR}=0.68(0.49$ to 0.94$)$ & $0.13(0.72), 0 \%$ & $52-130$ & Moderate $^{c}$ \\
\hline Relapse (any) & $k=1, n=414$ & $\mathrm{RR}=0.99(0.84$ to 1.17$)$ & & 52 & $\operatorname{LoW}^{\mathrm{b}, \mathrm{c}}$ \\
\hline \multicolumn{6}{|l|}{$\begin{array}{l}\text { Integrated cognitive and } \\
\text { interpersonal therapy }\end{array}$} \\
\hline Depression symptoms & $k=1, n=193$ & $\mathrm{SMD}=-0.64(-1.19$ to -0.09$)$ & NA & 20 & Low ${ }^{c}$ \\
\hline Mania symptoms & $k=1, n=193$ & $\mathrm{SMD}=-0.10(-0.30$ to 0.10$)$ & NA & 20 & LOW $^{b, c}$ \\
\hline \multicolumn{6}{|c|}{$\begin{array}{l}\text { NA, not applicable; RR, risk ratio; SMD, standardised mean difference. } \\
\text { a. Risk of bias. } \\
\text { b. Publication/reporting bias. } \\
\text { c. Imprecision. } \\
\text { d. Inconsistency. }\end{array}$} \\
\hline
\end{tabular}

be associated with a reduction in admissions to hospital, but the confidence interval was compatible with both a reduction and an increase in the effect. ${ }^{34,64,68,69}$

\section{Group psychological interventions}

The search identified 12 RCTs $(n=914)$ of group interventions including psychoeducation, ${ }^{49,70-73} \mathrm{CBT},{ }^{32,74,75}$ mindfulness therapy, ${ }^{76,77}$ social cognition and interaction training, ${ }^{78}$ and dialectical behaviour therapy. ${ }^{44}$ Interventions were compared with treatment as usual except for two studies that compared psychoeducation with attention control. ${ }^{70,71}$ In ten trials participants were euthymic at baseline, ${ }^{32,70-78}$ one study included participants experiencing an acute episode of mania or depression, ${ }^{49}$ and another included people with current depression. Eight trials $(n=423)$ reported very low-quality evidence of a small effect on depression outcomes at post-treatment favouring group interventions. $^{32,44,49,73,75-78}$ Six trials $(n=375)$ found no effect on

\begin{tabular}{|c|c|c|c|c|c|}
\hline Outcome & $\begin{array}{l}\text { Number of studies (k) } \\
\text { and participants (n) }\end{array}$ & Effect size $(95 \% \mathrm{Cl})$ & $\begin{array}{l}\text { Heterogeneity } \\
\chi^{2}(P), I^{2}\end{array}$ & $\begin{array}{l}\text { Intervention } \\
\text { length, weeks }\end{array}$ & $\begin{array}{l}\text { Quality } \\
\text { (GRADE) }\end{array}$ \\
\hline \multicolumn{6}{|l|}{ Family-focused therapy } \\
\hline Depression symptoms & $k=1, n=79$ & $\mathrm{SMD}=-0.40(-0.80$ to 0.00$)$ & NA & 39 & Low $^{a, b}$ \\
\hline Mania symptoms & $k=1, n=79$ & $\mathrm{SMD}=0.00(-0.40$ to 0.40$)$ & NA & 39 & Low $^{a, b}$ \\
\hline Relapse (any) & $k=1, n=53$ & $\mathrm{RR}=0.89(0.52$ to 1.54$)$ & NA & 39 & Low $^{b}$ \\
\hline Hospital admission & $k=1, n=53$ & $\mathrm{RR}=0.71$ (0.33 to 1.52$)$ & NA & 39 & LoW $^{\mathrm{b}}$ \\
\hline \multicolumn{6}{|l|}{ CBT } \\
\hline Depression symptoms & $k=1, n=76$ & $S M D=0.41(0.12$ to 0.70$)$ & NA & 39 & Low $^{b, c}$ \\
\hline Mania symptoms & $k=1, n=76$ & $S M D=0.20(-0.11$ to 0.51$)$ & NA & 39 & Low $^{\mathrm{b}, \mathrm{c}}$ \\
\hline Relapse (any) & $k=1, n=76$ & $\mathrm{RR}=0.60$ (0.34 to 1.05$)$ & NA & 39 & Low $^{b, c}$ \\
\hline \multicolumn{6}{|l|}{ IPSRT } \\
\hline Depression symptoms & $k=1, n=25$ & $\mathrm{SMD}=0.44(-0.34$ to 1.22$)$ & NA & 12 & Very low $w^{a, b}$ \\
\hline Relapse (any) & $k=1, n=41$ & $\mathrm{RR}=1.55(0.63$ to 3.84$)$ & NA & 123 & Very low ${ }^{a, b}$ \\
\hline Response (any) & $k=1, n=25$ & $\mathrm{RR}=0.98(0.60$ to 1.60$)$ & NA & 12 & Very low $w^{a, b}$ \\
\hline \multicolumn{6}{|l|}{ Integrated group therapy } \\
\hline Depression symptoms & $k=1, n=61$ & $\mathrm{SMD}=-0.35(-0.85$ to 0.16$)$ & NA & 12 & Very low ${ }^{b, c, c}$ \\
\hline Mania symptoms & $k=1, n=61$ & $S M D=-0.17(-0.68$ to 0.33$)$ & NA & 12 & Very low $w^{b, c, c}$ \\
\hline \multicolumn{6}{|c|}{$\begin{array}{l}\text { CBT, cognitive-behavioural therapy; IPSRT, Interpersonal and social rhythm therapy; NA, not applicable; RR, risk ratio; SMD, standardised mean difference. } \\
\text { a. Risk of bias. } \\
\text { b. Imprecision. } \\
\text { c. Publication/reporting bias. } \\
\text { d. Indirectness. }\end{array}$} \\
\hline
\end{tabular}




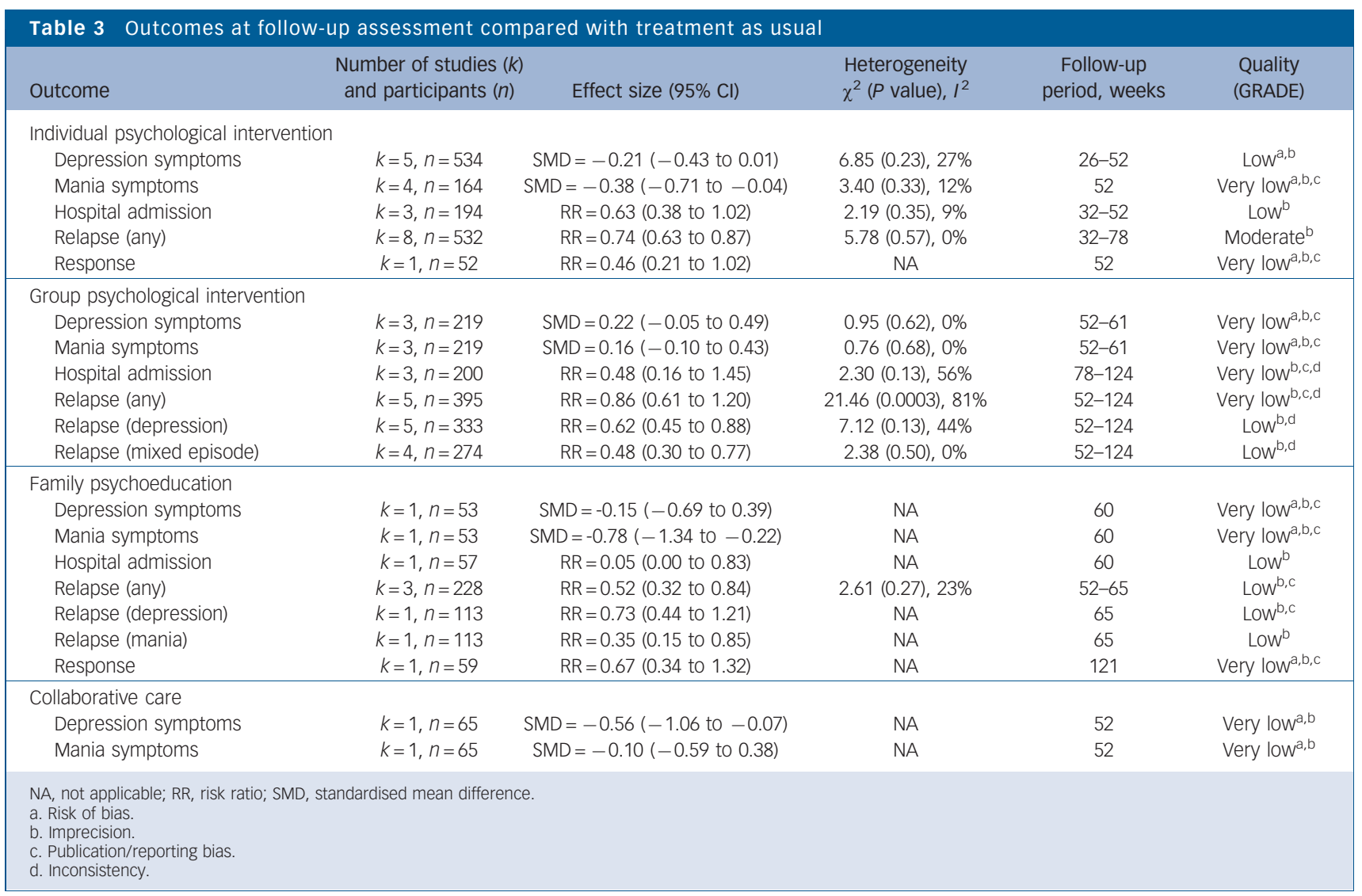

mania symptoms..$^{32,49,73,75,76,78}$ Furthermore, the two studies comparing psychoeducation with attention control $(n=170)$ found low-quality evidence for a reduction in any type of relapse, but the confidence interval was compatible with both a reduction and an increase in the effect. ${ }^{70,71}$ The two studies did find evidence for a reduction in depressive and manic relapses. Also, the two studies together with a trial comparing CBT with treatment as usual ( $n=205)$ reported low-quality evidence that group interventions might be associated with a reduction in hospital admissions, but the confidence interval was compatible with both a reduction and increase in the effect. ${ }^{70,71,75}$ Results at follow-up in five studies $(n=333)$ reported low-quality evidence of a reduction in depressive relapses. ${ }^{70,71,73,74,76}$ Also, four studies $(n=274)$ reported a reduction of relapses into mixed episodes. ${ }^{70,71,73,74}$ However, effects on depressive symptoms, ${ }^{32,73,76}$ and on hospital admission, ${ }^{70,71}$ were inconclusive.

\section{Family psychoeducation}

The search identified seven RCTs $(n=409)$ of family psychoeducation. Two trials included psychoeducation for participants and their family members, ${ }^{50,79}$ and in five trials only family

\begin{tabular}{|c|c|c|c|c|c|}
\hline Outcome & $\begin{array}{l}\text { Number of studies }(k) \\
\text { and participants }(n)\end{array}$ & Effect size $(95 \% \mathrm{Cl})$ & Heterogeneity & $\begin{array}{l}\text { Follow-up period } \\
\text { (weeks) }\end{array}$ & $\begin{array}{l}\text { Quality } \\
\text { (GRADE) }\end{array}$ \\
\hline \multicolumn{6}{|l|}{ Family-focused therapy } \\
\hline Depression symptoms & $k=1, n=79$ & $\mathrm{SMD}=-0.10(-0.56$ to 0.36$)$ & NA & 52 & Very low ${ }^{a, b, c}$ \\
\hline Mania symptoms & $k=1, n=79$ & $\mathrm{SMD}=-0.30(-0.68$ to 0.08$)$ & NA & 52 & Very low ${ }^{a, b}$ \\
\hline Relapse (any) & $k=1, n=101$ & $\mathrm{RR}=0.67(0.34$ to 1.30$)$ & NA & 52 & Very low ${ }^{a, b, c}$ \\
\hline Response (any) & $k=1, n=62$ & $\mathrm{RR}=1.15$ (0.68 to 1.94$)$ & NA & 121 & Very low ${ }^{a, b, c}$ \\
\hline Hospital admission & $k=1, n=38$ & $\mathrm{RR}=0.24$ (0.08 to 0.74$)$ & NA & 104 & very low ${ }^{a, b}$ \\
\hline \multicolumn{6}{|l|}{ CBT } \\
\hline Depression symptoms & $k=1, n=76$ & $\mathrm{SMD}=0.49$ (0.04 to 0.94$)$ & NA & 143 & Very low ${ }^{b, c}$ \\
\hline Relapse (any) & $k=1, n=76$ & $\mathrm{RR}=1.13(0.81$ to 1.58$)$ & NA & 143 & Very low ${ }^{b, c}$ \\
\hline \multicolumn{6}{|l|}{ IPSRT } \\
\hline Response (depression) & $k=1, n=192$ & $\mathrm{RR}=0.73(0.50$ to 1.07$)$ & NA & 52 & Very low ${ }^{a, b, c}$ \\
\hline \multicolumn{6}{|l|}{$\begin{array}{l}\text { Integrated group therapy } \\
\text { (v. group drug counselling) }\end{array}$} \\
\hline Depression symptoms & $k=1, n=61$ & $\mathrm{SMD}=0.11(-0.39$ to 0.61$)$ & NA & 26 & Very low ${ }^{b, c, d}$ \\
\hline Mania symptoms & $k=1, n=61$ & $\mathrm{SMD}=-0.53(-1.05$ to -0.02$)$ & NA & 26 & Very low $w^{b, c, d}$ \\
\hline \multicolumn{6}{|c|}{$\begin{array}{l}\text { CBT, cognitive-behavioural therapy; IPSRT, interpersonal and social rhythm therapy; NA, not applicable; RR, risk ratio; SMD, standardised mean difference. } \\
\text { a. Risk of bias. } \\
\text { b. Imprecision. } \\
\text { c. Publication/reporting bias. } \\
\text { d. Indirectness. }\end{array}$} \\
\hline
\end{tabular}


members received psychoeducation. ${ }^{57,80-83}$ Interventions were compared with treatment as usual. Five trials enrolled participants who were euthymic at baseline, one trial enrolled participants who were experiencing acute episode of mania or depression or were euthymic at baseline, ${ }^{57}$ and another included only participants who were in an acute episode of mania or depression. ${ }^{50}$ One trial $(n=43)$ found low-quality evidence of medium effect in reduction of depressive and manic symptoms favouring family psychoeducation at post-treatment. ${ }^{57}$ At follow-up, three trials $(n=228)$ reported low-quality evidence of a reduction in relapse. ${ }^{79,80,82}$ One trial $(n=113)$ reported a reduction in mania relapses. ${ }^{82}$ One study $(n=57)$ reported a very large effect on reduction of the number of hospital admissions, but there were only nine events in the study. ${ }^{80}$

\section{Collaborative care}

The search identified five RCTs $(n=1058)$ of collaborative care compared with treatment as usual. Two started with euthymic participants, ${ }^{47,84}$ and three recruited participants experiencing an episode.$^{53-55}$ In comparison with treatment as usual, two trials $(n=123)$ reported low-quality evidence of a small effect favouring collaborative care on depressive symptoms and no effect on mania symptoms at post-treatment, but the effect estimates were imprecise. ${ }^{53,54}$ One trial $(n=234)$ found no difference in reduction of relapse. ${ }^{55}$ However, two trials $(n=572)$ reported moderate-quality evidence suggesting collaborative care reduced the number of admissions to hospital at post-treatment. ${ }^{55,84}$

\section{Integrated cognitive and interpersonal therapy}

The search identified one RCT $(n=212)$ with a group of participants who were randomised to integrated cognitive and interpersonal therapy or treatment as usual. ${ }^{33}$ Participants in the intervention group could choose to follow individual or group integrated cognitive and interpersonal therapy. Outcome data were presented for the whole intervention group $v$. treatment as usual. The trial reported low-quality evidence at post-treatment of a medium effect favouring the intervention on depressive symptoms and no effect on mania symptoms.

\section{Family-focused therapy}

The search identified four RCTs $(n=357)$ on family-focused therapy compared with psychoeducation, collaborative therapy or treatment as usual. Participants were euthymic, ${ }^{85}$ in an episode or euthymic, ${ }^{56}$ only depressed, ${ }^{43}$ or in any type of episode. ${ }^{50}$ Posttreatment data were of low quality. One study $(n=79)$ found no effect of family-focused therapy compared with treatment as usual on manic symptoms and a medium effect on depressive symptoms (although the confidence interval was also compatible with no effect). ${ }^{56} \mathrm{~A}$ small effect was found on relapse in a study $(n=53)$ comparing family-focused therapy with psychoeducation, but the confidence interval was compatible with both a reduction and increase in the effect. ${ }^{85}$ The confidence in the follow-up results were very low.

\section{CBT v. supportive therapy}

The search identified one RCT $(n=76)$ comparing individual CBT with supportive therapy; the quality of the evidence was low. ${ }^{86} \mathrm{At}$ post-treatment a medium effect was found of supportive therapy on depressive symptoms. Also, a small effect was found of supportive therapy on mania symptoms, but CBT reduced the risk of relapse. However, the confidence intervals for the mania and relapse outcomes were compatible with either a reduction or an increase in the true effect.

\section{IPSRT $v$. active control}

The search identified three RCTs $(n=299)$ of IPSRT compared with quetiapine therapy, intensive clinical management or treatment as usual. Participants in all three trials were in a depressive episode at baseline. ${ }^{43,45,48}$ One study reported a small effect of quetiapine compared with IPSRT on symptoms of depression at post-treatment, but the confidence interval was compatible with both a reduction and an increase in the effect. ${ }^{45} \mathrm{~A} 123$-week trial $(n=41)$ found effects that were in favour of intensive clinical management compared with IPSRT on a reduction in relapses, but the confidence interval was compatible with both a reduction and increase in the effect. ${ }^{48}$ All results were of very low quality.

\section{Integrated group therapy $v$. group counselling}

The search identified one RCT $(n=61)$ including people with both bipolar disorder and a comorbid substance use disorder who were either euthymic or acutely depressed at baseline. It compared integrated group therapy with group drug counselling. ${ }^{58}$ At post-treatment there was very low-quality evidence of a small effect on depressive and mania symptoms, but confidence intervals were compatible with either a reduction or an increase in symptoms. There was very low-quality evidence of a moderate effect on mania symptoms at follow-up.

\section{Discussion}

This is the first comprehensive systematic review and meta-analysis of the full range of psychological interventions that have been evaluated for the treatment of people with bipolar disorder. The evidence suggests that some, but not all, psychological treatments reduce relapse rates and hospital admissions, and they may improve depressive symptoms. In particular, we found moderate-quality evidence that individual psychological interventions were associated with a $34 \%$ reduction in the risk of relapse at the end of treatment, sustained at $26 \%$ reduction in risk at follow-up. There was also low-quality evidence that individual psychological treatment reduced symptoms of depression, but the reduction may be small. Although the evidence was not as robust, group psychoeducation also showed beneficial effects for reducing risk of relapse, and perhaps for some symptomatic improvement. We also found a substantial reduction in relapse rates for people who received family psychoeducation, although the quality of the evidence for this finding was also low. In addition, our analysis of collaborative care showed moderate-quality evidence for a $32 \%$ reduction in admissions to hospital. We found little impact on symptoms of mania, quality of life, psychological functioning or other treatment outcomes, although in most cases the underpinning evidence was very low quality and therefore inconclusive. Moreover, we found no evidence of benefit for other types of psychological interventions such as IPSRT. These results confirm and extend the findings of previous, smaller and narrower reviews of specific psychological treatments for bipolar disorder, ${ }^{14,15,17-19}$ and suggest that as the size of the evidence base has increased, the beneficial effects of some psychological interventions have become more apparent. Previous reviews included 10 or fewer trials and fewer than 1000 participants; in contrast, this review analysed 55 trials including data from 6010 participants. Overall, on the basis of this review, we would recommend the use of psychological interventions in the treatment of people with bipolar disorder to reduce relapse rates and to reduce depressive 
symptoms. Although there is insufficient evidence to recommend one specific treatment over the others, the best evidence is for individual structured psychological interventions, and there is weaker - but still promising - evidence for group and family interventions and for collaborative care.

Our results are consistent with other recent reviews showing that psychological approaches may reduce transition to psychosis, including for people with bipolar disorder, ${ }^{87}$ and that family psychological interventions reduce relapse rates in both early and established schizophrenia. ${ }^{88,89}$ Additionally, psychological interventions are the most effective interventions for people with major depression. ${ }^{90}$ The effectiveness of psychological interventions in these closely related conditions is promising for the treatment of bipolar disorder, and effective psychological strategies for people with bipolar disorder could be clinically and economically important.

\section{Strengths and limitations}

Participants in our review were similar to those in 'real world' practice in several ways. For example, the proportions of men and women and of people with type 1 and type 2 bipolar disorder in the included studies were comparable with epidemiological samples. ${ }^{4,5}$ Most studies recruited participants from out-patient or community settings, where these psychological interventions could be carried out. Few studies were undertaken outside Europe and North America, and the effects of psychological interventions might differ in places with different healthcare systems and different levels of community support.

Although the evidence provides support for the use of psychological interventions in the treatment of people with bipolar disorder, our meta-analysis includes a number of trials with participants in different phases: sometimes euthymic, sometimes depressive, sometimes a mixture of both and sometimes a mixture of depressive and manic. Most of the trials with participants in different phases of the illness did not report disaggregated data for people in the euthymic and the depressive phases, or for people with depression and people who were experiencing mania at the start of the trial. This is likely to lead to underestimating the effects on symptoms; people who are euthymic are without symptoms, thereby diluting the mean impact of psychological intervention on depressive and manic symptoms in these mixed populations. Similarly, where data on relapse included trials in which participants were in a manic phase, this may have led to underestimating the impact on relapse rates; people who are manic are often difficult to engage in any psychological treatment, thereby diluting the effects of psychological therapy on relapse rates for those who are euthymic or depressed. In addition, the lack of disaggregated data on outcomes for people with mania makes it impossible to identify any possible harm or benefit of psychological therapies for this group. Finally, a limitation of including participants at different phases of illness is that we are not comparing like with like. Although statistical heterogeneity was minimal, summary effects should be interpreted with some caution in light of the clinical differences among participants across trials.

A further potential limitation of this analysis is the quality of the data. In some comparisons evidence for different outcomes was not consistent. For example, a psychological intervention might appear to reduce symptoms but have no effect on treatment response. Some trials were not registered, and there was evidence of selective reporting of outcomes, which could lead us to overestimate the benefits of psychological treatments in much the same way as selective publishing of drug studies has led to overestimating their true effectiveness. ${ }^{91}$ Using GRADE to evaluate the quality of evidence underpinning each outcome, we incorporated these limitations in our evaluation of the results and restricted our conclusions to outcomes based on low- and moderate-quality evidence; importantly, evidence for key outcomes - relapse rates and symptoms - was better than evidence for most secondary outcomes. Almost all reviewed psychotherapies were given as adjuncts to pharmacotherapy (monotherapy or combinations of various medications), and they were delivered in a variety of different treatment modalities and service settings. Co-interventions and details about service settings were incompletely described in many trials and could contribute to unobserved heterogeneity. In addition, although statistical heterogeneity was minimal and there is a consensus that psychological treatments for bipolar disorder share many common elements and strategies (e.g. coping strategies for mood changes), they nevertheless differ in complexity, the skill and training required, content and duration, even when they bear the same name (e.g. CBT or psychoeducation). These problems may be addressed in further research in this rapidly expanding field.

\section{Implications for practice}

On the basis of this review, individual psychological interventions should be offered (in addition to whatever pharmacological interventions people already receive) with the aim of reducing relapse rates in people with bipolar disorder who are depressed or euthymic and for improving symptoms in people with depression. Although the evidence was limited for many outcomes in this review, there is strong evidence of the effectiveness of psychological interventions for major depression, ${ }^{90}$ adding some support to the view that bipolar depression may be treated effectively with psychological treatment. It is also worth considering family psychological interventions, not just because the trials show some promise, but also because the benefits of family interventions for psychosis (including schizophrenia and bipolar disorder) suggest that relapse rates can be reduced in both early and later psychosis. ${ }^{88,89}$ It seems likely, on the basis of this broader evidence as well as the evidence in this review, that family interventions could be beneficial for people with bipolar disorder and should be made available routinely to help reduce relapse rates. People with bipolar disorder may also benefit from group psychoeducation and from collaborative care. It is important to keep in mind that people with bipolar disorder are often only partially adherent to pharmacotherapy, which may contribute to the recurrence of symptoms and to relapse. ${ }^{92}$ Group or family psychoeducational interventions and collaborative care could help these people develop skills related to medication use, stress management, recognising early symptoms and coping with symptoms. Such skills could reduce risk of relapse and improve response.

Worldwide there are few people with training and experience in delivering specific psychological interventions for individuals with bipolar depression. However, there are many therapists providing evidence-based treatments for major depressive disorder in primary care. Because the rationale and process of delivering CBT are similar for the two forms of depression, it might be sensible for therapists in primary care to provide individual CBT for people with bipolar depression if they have experience in managing people with bipolar disorder or are supervised by clinicians with that experience. Many of the skills learned through CBT for depression could also help people with bipolar disorder who are euthymic to avoid relapse. In the long term service providers and educational institutions should endeavour to increase the number of therapists trained specifically in the treatment of bipolar depression and the prevention of bipolar relapse. 


\section{Directions for future research}

Although this review supports the use of individual psychological intervention for relapse reduction and symptom improvement, we do not have sufficient information to know the impact on functioning and quality of life, both key concerns for people with bipolar disorder. Further research should include sufficiently large populations to address these critical outcomes. The same is true for family interventions. Longer follow-up is needed to establish how well the effects of all of these interventions endure. Further research is needed to understand how psychological interventions compare with each other at each phase of the illness. Future studies could be improved by reporting results separately for people in different phases of the disorder (who are at risk of different outcomes), better describing treatments and comparators, pre-registering trials, completely and transparently reporting all outcomes measured, and standardising the use of outcome measurement. Moreover, including an economic (cost-benefit) analysis in trials, especially when there is a possible reduction in relapse, would add greatly to our understanding of what we can do to help people with bipolar disorder; comparing the costeffectiveness of individual and group approaches would address common concerns about method of delivery.

There is little, if any, evidence about which psychological treatments could be beneficial for people with more severe forms of bipolar disorder. More research could address the treatment of people who have frequent episodes, people who are most severely functionally disabled, and people with persisting inter-episode symptoms. People who are admitted to hospital because of mania symptoms usually receive pharmacotherapy, and we identified no trial that examined whether a psychological intervention would be beneficial during this phase of the illness. Following this review, further research can be developed on the basis of much stronger evidence than was available only a few years ago. It is clear that psychological interventions now have an important place alongside medication in the treatment of people with bipolar disorder, and future research will elucidate the most effective ways to deliver psychotherapy.

\footnotetext{
Matthijs Oud, MSC, Department of Care Innovation, Trimbos Institute, Utrecht, The Netherlands: Evan Mayo-Wilson, MPA, DPhil, Center for Clinical Trials and Evidence Netherlands; Evan Mayo-Wilson, MPA, DPhil, Center for Clinical Trials and Evid
Synthesis, Johns Hopkins Bloomberg School of Public Health, Baltimore, USA; Ruth Braidwood, MSc, Department of Clinical, Educational and Health Psychology, University College London, UK; Peter Schulte, MD, PhD, Treatment Centre for Bipolar Disorders, Mental Health Service Noord-Holland-Noord, Alkmaar, The Netherlands; Steven H. Jones, PhD, Department of Clinical Psychology, Spectrum Centre for Mental Health Research, Lancaster University, UK; Richard Morriss, MD, FRCPsych, Department of Psychiatry and Community Mental Health, Institute of Mental Health, University of Nottingham, UK; Ralph Kupka, MD, PhD, Department Mental Health, University of Nottingham, UK; Ralph Kupka, MD, PhD, Department
of Psychiatry, VU University Medical Centre, Amsterdam, The Netherlands; Pim Cuijpers, PhD, Faculty of Psychology and Education, VU University Amsterdam, The Netherlands; Tim Kendall, FRCPsych, National Collaborating Centre for Mental Health, London, UK

Correspondence: Matthijs Oud, Trimbos Institute, Department of Care Innovation, Da Costakade 45, 3521 VS, Utrecht, The Netherlands. Email: moud@trimbos.nl

First received 15 Sep 2014, final revision 19 Apr 2015, accepted 23 Apr 2015
}

\section{Funding}

The National Collaborating Centre for Mental Health (NCCMH) receives $£ 1.4$ million per year from the National Institute for Health and Care Excellence (NICE) to develop guidelines for the treatment of mental health problems. Trimbos Institute received €242562 from the Netherlands Psychiatric Association (NVvP) to develop the Guideline for the Diagnosis and Treatment of Bipolar Disorder. The views of the authors expressed in this paper do not necessarily reflect the views of NICE, NCCMH, the Royal College of Psychiatrists, Trimbos Institute or NVvP.

\section{Acknowledgements}

We acknowledge the Dutch and English Guideline Development Groups for their assistance in the review process.

\section{References}

1 Judd LL, Akiskal HS. The prevalence and disability of bipolar spectrum disorders in the US population: re-analysis of the ECA database taking into account subthreshold cases. J Affect Disord 2003; 73: 123-31.

2 Ten Have M, Vollebergh W, Bijl R, Nolen WA. Bipolar disorder in the general population in The Netherlands (prevalence, consequences and care utilisation): results from The Netherlands Mental Health Survey and Incidence Study (NEMESIS). J Affect Disord 2002; 68: 203-13.

3 Grant BF, Stinson FS, Hasin DS, Dawson DA, Chou SP, Ruan WJ, et al. Prevalence, correlates, and comorbidity of bipolar I disorder and axis I and II disorders: results from the National Epidemiologic Survey on Alcohol and Related Conditions. J Clin Psychiatry 2005; 66: 1205-15.

4 Merikangas KR, Jin R, He JP, Kessler RC, Lee S, Sampson NA, et al. Prevalence and correlates of bipolar spectrum disorder in the world mental health survey initiative. Arch Gen Psychiatry 2011; 68: 241-51.

5 Merikangas KR, Akiskal HS, Angst J, Greenberg PE, Hirschfeld RM, Petukhova $\mathrm{M}$, et al. Lifetime and 12-month prevalence of bipolar spectrum disorder in the National Comorbidity Survey replication. Arch Gen Psychiatry 2007; 64: 543-52.

6 American Psychiatric Association. Practice guideline for the treatment of patients with bipolar disorder (revision). Am J Psychiatry 2002; 159 (suppl 4): $1-50$.

7 Goetzel RZ, Hawkins K, Ozminkowski RJ, Wang S. The health and productivity cost burden of the 'top 10' physical and mental health conditions affecting six large U.S. employers in 1999. J Occup Environ Med 2003; 45: 5-14.

8 Arts B, Jabben N, Krabbendam L, van Os J. Meta-analyses of cognitive functioning in euthymic bipolar patients and their first-degree relatives. Psychol Med 2008; 38: 771-85.

9 Dilsaver SC. An estimate of the minimum economic burden of bipolar I and II disorders in the United States: 2009. J Affect Disord 2011; 129: 79-83.

10 McCrone P, Dhanasiri S, Patel A, Knapp M, Lawton-Smith S. Paying the Price: the Cost of Mental Health Care in England to 2026. King's Fund, 2008.

11 Angst F, Stassen $\mathrm{HH}$, Clayton PJ, Angst J. Mortality of patients with mood disorders: follow-up over 34-38 years. J Affect Disord 2002; 68: 167-81.

12 Judd LL, Akiskal HS, Schettler PJ, Endicott J, Maser J, Solomon DA, et al. The long-term natural history of the weekly symptomatic status of bipolar I disorder. Arch Gen Psychiatry 2002; 59: 530-7.

13 Gitlin MJ, Swendsen J, Heller TL, Hammen C. Relapse and impairment in bipolar disorder. Am J Psychiatry 1995; 152: 1635-40.

14 Gregory VL. Cognitive-behavioral therapy for depression in bipolar disorder: a meta-analysis. J Evid Based Soc Work 2010; 7: 269-79.

15 Gregory VL. Cognitive-behavioral therapy for mania: a meta-analysis of randomized controlled trials. Soc Work Ment Health 2010; 8: 483-94.

16 Szentagotai A, David D. The efficacy of cognitive-behavioral therapy in bipolar disorder: a quantitative meta-analysis. J Clin Psychiatry 2010; 71: 66-72.

17 Lam DH, Burbeck R, Wright K, Pilling S. Psychological therapies in bipolar disorder: the effect of illness history on relapse prevention - a systematic review. Bipolar Disord 2009; 11: 474-82.

18 Morriss RK, Faizal MA, Jones AP, Williamson PR, Bolton C, McCarthy JP. Interventions for helping people recognise early signs of recurrence in bipolar disorder. Cochrane Database Syst Rev 2007; 1: CD004854.

19 Justo LP, Soares BG, Calil HM. Family interventions for bipolar disorder. Cochrane Database Syst Rev 2007; 4: CD005167.

20 National Institute for Health and Care Excellence. Bipolar Disorder: The Management of Bipolar Disorder in Adults, Children and Adolescents, in Primary and Secondary Care. Clinical Guideline CG185. NICE, 2014.

21 Kupka A, Goossens $P$, van Bendegem $M$, Daemen $P$, Daggenvoorde $T$, Daniels $\mathrm{M}$, et al. Multidisciplinaire Richtlijn Bipolaire Stoornissen [Multidisciplinary Guidelines for Bipolar Disorders]. Trimbos Institute, 2015.

22 Moher D, Liberati A, Tetzlaff J, Altman DG. Reprint - preferred reporting items for systematic reviews and meta-analyses: the PRISMA statement. Phys Ther 2009; 89: 873-80.

23 Higgins JPT, Green S. Cochrane Handbook for Systematic Reviews of Interventions. Wiley Blackwell, 2008.

24 Tohen M, Frank E, Bowden CL, Colom F, Ghaemi SN, Yatham LN, et al. The International Society for Bipolar Disorders (ISBD) Task Force report on the nomenclature of course and outcome in bipolar disorders. Bipolar Disord 2009; 11: 453-73.

25 Miklowitz DJ, Goodwin GM, Bauer MS, Geddes JR. Common and specific elements of psychosocial treatments for bipolar disorder: a survey of clinicians participating in randomized trials. J Psychiatr Pract 2008; 14 77-85. 
26 Nordic Cochrane Centre. Review Manager (RevMan) Version 5.2. Cochrane Collaboration, 2012.

27 Guyatt GH, Oxman AD, Schunemann HJ, Tugwell P, Knottnerus A. GRADE guidelines: a new series of articles in the Journal of Clinical Epidemiology. J Clin Epidemiol 2011; 64: 380-2.

28 Jackson HJ, McGorry PD, Killackey E, Bendall S, Allott K, Dudgeon P, et al. Acute-phase and 1-year follow-up results of a randomized controlled trial of CBT versus Befriending for first-episode psychosis: the ACE project. Psychol Med 2008; 38: 725-35

29 Pickett-Schenk SA, Lippincott RC, Bennett C, Steigman PJ. Improving knowledge about mental illness through family-led education: the journey of hope. Psychiatr Serv 2008; 59: 49-56.

30 Staring $A B$, Van der Gaag M, Koopmans GT, Selten JP, Van Beveren JM, Hengeveld MW, et al. Treatment adherence therapy in people with psychotic disorders: randomised controlled trial. Br J Psychiatry 2010; 197: 448-55.

31 Lieberman DZ, Kelly TF, Douglas L, Goodwin FK. A randomized comparison of online and paper mood charts for people with bipolar disorder. J Affect Disord 2010; 124: 85-9.

32 Bernhard B. Wirksamkeit einer kognitiv-psychoedukativen Gruppenintervention bei bipolaren Patienten [Effectiveness of cognitive psychoeducational group interventions in bipolar patients]. PhD dissertation. Faculty of Medicine, Ludwig Maximillians University, 2009.

33 Schwannauer M. Cognitive, interpersonal and psychosocial factors influencing vulnerability, treatment outcome and relapse in bipolar affective disorders: a clinical randomised controlled treatment trial. PhD thesis, University of Edinburgh, 2007.

34 Jones SH, Smith G, Mulligan LD, Lobban F, Law H, Dunn G, et al. Recoveryfocused cognitive-behavioural therapy for recent-onset bipolar disorder: randomised controlled pilot trial. Br J Psychiatry 2015; 206: 58-66.

35 Todd NJ, Jones SH, Hart A, Lobban FA. A web-based self-management intervention for Bipolar Disorder 'living with bipolar': a feasibility randomised controlled trial. J Affect Disord 2014; 169: 21-9.

36 De Barros Pellegrinelli K, de O Costa LF, Silval KID, Dias VV, Roso MC Bandeira $\mathrm{M}$, et al. Efficacy of psychoeducation on symptomatic and functional recovery in bipolar disorder. Acta Psychiatr Scand 2013; 127: 153-8.

37 Glick ID, Clarkin JF, Haas GL, Spencer JH. Clinical significance of inpatient family intervention: conclusions from a clinical trial. Hosp Community Psychiatry 1993; 44: 869-73.

38 Clarkin JF, Carpenter D, Hull J, Wilner P, Glick I. Effects of psychoeducational intervention for married patients with bipolar disorder and their spouses. Psychiatr Serv 1998; 49: 531-3.

39 Parikh SV, Zaretsky A, Beaulieu S, Yatham LN, Young LT, Patelis-Siotis I, et al. A randomized controlled trial of psychoeducation or cognitive-behavioral therapy in bipolar disorder: a Canadian Network for Mood and Anxiety treatments (CANMAT) study [CME]. J Clin Psychiatry 2012; 73: 803-10.

40 Fagiolini A, Frank E, Axelson DA, Birmaher B, Cheng Y, Curet DE, et al. Enhancing outcomes in patients with bipolar disorder: results from the Bipolar Disorder Center for Pennsylvanians Study. Bipolar Disord 2009; 11: 382-90

41 Weiss RD, Griffin ML, Kolodziej ME, Greenfield SF, Najavits LM, Daley DC, et al A randomized trial of integrated group therapy versus group drug counseling for patients with bipolar disorder and substance dependence. Am J Psychiatry 2007; 164: 100-7.

42 Eker $\mathrm{F}$, Harkin S. Effectiveness of six-week psychoeducation program on adherence of patients with bipolar affective disorder. J Affect Disord 2012; 138: 409-16.

43 Miklowitz DJ, Otto MW, Frank E, Reilly-Harrington NA, Wisniewski SR, Kogan JN, et al. Psychosocial treatments for bipolar depression: a 1-year randomized trial from the Systematic Treatment Enhancement Program. Arch Gen Psychiatry 2007; 64: 419-26.

44 Van Dijk S, Jeffrey J, Katz MR. A randomized, controlled, pilot study of dialectical behavior therapy skills in a psychoeducational group for individuals with bipolar disorder. J Affect Disord 2013; 145: 386-93.

45 Swartz HA, Frank E, Cheng Y. A randomized pilot study of psychotherapy and quetiapine for the acute treatment of bipolar II depression. Bipolar Disord 2012; 14: 211-6.

46 Schmitz JM, Averill P, Sayre SU, Mccleary P, Moeller FG, Swann A. Cognitive-behavioral treatment of bipolar disorder and substance abuse: a preliminary randomized study. Addict Disord Their Treat 2002; 1: 17-24.

47 Bauer MS, McBride L, Williford WO, Glick H, Kinosian B, Altshuler L, et al. Collaborative care for bipolar disorder: Part I. Intervention and implementation in a randomized effectiveness trial. Psychiatr Serv 2006; 57 927-36.
48 Frank E, Swartz HA, Mallinger AG, Thase ME, Weaver EV, Kupfer DJ. Adjunctive psychotherapy for bipolar disorder: effects of changing treatment modality. J Abnorm Psychol 1999; 108: 579-87.

49 Sajatovic M, Davies MA, Ganocy SJ, Bauer MS, Cassidy KA, Hays RW, et al A comparison of the life goals program and treatment as usual for individuals with bipolar disorder. Psychiatr Serv 2009; 60: 1182-9.

50 Miller IW, Solomon DA, Ryan CE, Keitner GI. Does adjunctive family therapy enhance recovery from bipolar I mood episodes? J Affect Disord 2004; 82: 431-6.

51 Scott J, Garland A, Moorhead S. A pilot study of cognitive therapy in bipolar disorders. Psychol Med 2001; 31: 459-67.

52 Scott J, Paykel E, Morriss R, Bentall R, Kinderman P, Johnson T, et al. Cognitive-behavioural therapy for severe and recurrent bipolar disorders: randomised controlled trial. Br J Psychiatry 2006; 188: 313-20.

53 Kilbourne AM, Post EP, Nossek A, Drill L, Cooley S, Bauer MS. Improving medical and psychiatric outcomes among individuals with bipolar disorder: a randomized controlled trial. Psychiatr Serv 2008; 59: 760-8.

54 Kilbourne AM, Goodrich DE, Lai Z, Clogston J, Waxmonsky J, Bauer MS. Life Goals Collaborative Care for patients with bipolar disorder and cardiovascular disease risk. Psychiatr Serv 2012; 63: 1234-8.

55 Simon GE, Ludman EJ, Unutzer J, Bauer MS, Operskalski B, Rutter C. Randomized trial of a population-based care program for people with bipolar disorder. Psychol Med 2005; 35: 13-24.

56 Miklowitz DJ, Simoneau TL, George EL, Richards JA, Kalbag A, Sachs-Ericsson N, et al. Family-focused treatment of bipolar disorder: 1-year effects of a psychoeducational program in conjunction with pharmacotherapy. Biol Psychiatry 2000; 48: 582-92.

57 Perlick DA, Miklowitz DJ, Lopez N, Chou J, Kalvin C, Adzhiashvili V, et al Family-focused treatment for caregivers of patients with bipolar disorder. Bipolar Disord 2010; 12: 627-37.

58 Weiss RD, Griffin ML, Jaffee WB, Bender RE, Graff FS, Gallop RJ, et al. A 'community-friendly' version of integrated group therapy for patients with bipolar disorder and substance dependence: a randomized controlled trial. Drug Alcohol Depend 2009; 104: 212-9.

59 Proudfoot J, Parker G, Manicavasagar V, Hadzi-Pavlovic D, Whitton A, Nicholas J, et al. Effects of adjunctive peer support on perceptions of illness control and understanding in an online psychoeducation program for bipolar disorder: a randomised controlled trial. J Affect Disord 2012; 142: 98-105.

60 Smith DJ, Griffiths E, Poole R, di Florio A, Barnes E, Kelly MJ, et al. Beating Bipolar: exploratory trial of a novel Internet-based psychoeducational treatment for bipolar disorder. Bipolar Disord 2011; 13: 571-7.

61 Dogan S, Sabanciogullari S. The effects of patient education in lithium therapy on quality of life and compliance. Arch Psychiatr Nurs 2003; 17 270-5.

62 Javadpour A, Hedayati A, Dehbozorgi GR, Azizi A. The impact of a simple individual psycho-education program on quality of life, rate of relapse and medication adherence in bipolar disorder patients. Asian J Psychiatr 2013; 6: 208-13.

63 Lobban F, Taylor L, Chandler C, Tyler E, Kinderman P, Kolamunnage-Dona R, et al. Enhanced relapse prevention for bipolar disorder by community mental health teams: cluster feasibility randomised trial. Br J Psychiatry 2010; 196: 59-63.

64 Perry A, Tarrier N, Morriss R, McCarthy E, Limb K. Randomised controlled trial of efficacy of teaching patients with bipolar disorder to identify early symptoms of relapse and obtain treatment. BMJ 1999; 318: 149-53.

65 Ball JR, Mitchell PB, Corry JC, Skillecorn A, Smith M, Malhi GS. A randomized controlled trial of cognitive therapy for bipolar disorder: focus on long-term change. J Clin Psychiatry 2006; 67: 277-86.

66 Zaretsky A, Lancee W, Miller C, Harris A, Parikh SV. Is cognitive-behavioural therapy more effective than psychoeducation in bipolar disorder? Can J Psychiatry 2008; 53: 441-8.

67 Lam DH, Bright J, Jones S, Hayward P, Schuck N, Chisholm D, et al. Cognitive therapy for bipolar illness: a pilot study of relapse prevention. Cogn Ther Res 2000; 24: 503-20.

68 Lam DH, Watkins ER, Hayward P, Bright J, Wright K, Kerr N, et al. A randomized controlled study of cognitive therapy for relapse prevention for bipolar affective disorder: outcome of the first year. Arch Gen Psychiatry 2003; 60: 145-52.

69 Cochran SD. Preventing medical noncompliance in the outpatient treatment of bipolar affective disorders. J Consult Clin Psychol 1984; 52: 873-8.

70 Colom F, Vieta E, Reinares M, Martinez-Aran A, Torrent C, Goikolea JM, et al. Psychoeducation efficacy in bipolar disorders: beyond compliance enhancement. J Clin Psychiatry 2003; 64: 1101-5.

71 Colom F, Vieta E, Martinez-Aran A, Reinares M, Goikolea JM, Benabarre A, et al. A randomized trial on the efficacy of group psychoeducation in the 
prophylaxis of recurrences in bipolar patients whose disease is in remission. Arch Gen Psychiatry 2003; 60: 402-7.

72 Torrent C, Bonnin Cdel M, Martinez-Aran A, Valle J, Amann BL, Gonzalez-Pinto A, et al. Efficacy of functional remediation in bipolar disorder: a multicenter randomized controlled study. Am J Psychiatry 2013; 170: 852-9.

73 Castle D, White C, Chamberlain J, Berk M, Berk L, Lauder S, et al. Groupbased psychosocial intervention for bipolar disorder: randomised controlled trial. Br J Psychiatry 2010; 196: 383-8.

74 Gomes BC, Abreu LN, Brietzke E, Caetano SC, Kleinman A, Nery FG, et al. A randomized controlled trial of cognitive behavioral group therapy for bipolar disorder. Psychother Psychosom 2011; 80: 144-50.

75 Costa RT, Cheniaux E, Range BP, Versiani M, Nardi AE. Group cognitive behavior therapy for bipolar disorder can improve the quality of life. Braz Med Biol Res 2012; 45: 862-8.

76 Perich T, Manicavasagar V, Mitchell PB, Ball JR, Hadzi-Pavlovic D. A randomized controlled trial of mindfulness-based cognitive therapy for bipolar disorder. Acta Psychiatr Scand 2013; 127: 333-43.

77 Williams JM, Alatiq Y, Crane C, Barnhofer T, Fennell MJ, Duggan DS, et al. Mindfulness-based Cognitive Therapy (MBCT) in bipolar disorder: preliminary evaluation of immediate effects on between-episode functioning. J Affect Disord 2008; 107: 275-9.

78 Lahera G, Benito A, Montes JM, Fernandez-Liria A, Olbert CM, Penn DL. Social cognition and interaction training (SCIT) for outpatients with bipolar disorder. J Affect Disord 2013; 146: 132-6.

79 D'Souza R, Piskulic D, Sundram S. A brief dyadic group based psychoeducation program improves relapse rates in recently remitted bipolar disorder: a pilot randomised controlled trial. J Affect Disord 2010; 120: $272-6$.

80 Bordbar MRF. Short-term family-focused psycho-educational program for bipolar mood disorder in Mashhad. Iran J Med Sci 2009; 34: 104-9

81 Madigan $\mathrm{K}$, Egan $\mathrm{P}$, Brennan $\mathrm{D}$, Hill $\mathrm{S}$, Maguire $\mathrm{B}$, Horgan $\mathrm{F}$, et al. A randomised controlled trial of carer-focussed multi-family group psychoeducation in bipolar disorder. Eur Psychiatry 2012; 27: 281-4.
82 Reinares M, Colom F, Sanchez-Moreno J, Torrent C, Martinez-Aran A, Comes $\mathrm{M}$, et al. Impact of caregiver group psychoeducation on the course and outcome of bipolar patients in remission: a randomized controlled trial. Bipolar Disord 2008; 10: 511-9.

83 Van Gent EM, Zwart FM. Psychoeducation of partners of bipolar-manic patients. J Affect Disord 1991; 21: 15-8.

84 Kessing LV, Hansen HV, Hvenegaard A, Christensen EM, Dam H, Gluud C, et al. Treatment in a specialised out-patient mood disorder clinic $v$. standard out-patient treatment in the early course of bipolar disorder: randomised clinical trial. Br J Psychiatry 2013; 202: 212-9.

85 Rea MM, Tompson MC, Miklowitz DJ, Goldstein MJ, Hwang S, Mintz J. Family-focused treatment versus individual treatment for bipolar disorder: results of a randomized clinical trial. J Consult Clin Psychol 2003; 71: 482-92.

86 Meyer TD, Hautzinger M. Cognitive behaviour therapy and supportive therapy for bipolar disorders: relapse rates for treatment period and 2-year follow-up. Psychol Med 2012; 42: 1429-39.

87 Stafford MR, Jackson H, Mayo-Wilson E, Morrison AP, Kendall T. Early interventions to prevent psychosis: systematic review and meta-analysis. BMJ 2013; 346: f185.

88 Bird V, Premkumar P, Kendall T, Whittington C, Mitchell J, Kuipers E. Early intervention services, cognitive-behavioural therapy and family intervention in early psychosis: systematic review. Br J Psychiatry 2010; 197: 350-6.

89 Pharoah F, Mari J, Rathbone J, Wong W. Family intervention for schizophrenia. Cochrane Database Syst Rev 2010; 12: CD000088.

90 National Institute for Health and Care Excellence. Depression in Adults; The Treatment and Management of Depression in Adults. Clinical Guidance CG90. NICE, 2009

91 Whittington CJ, Kendall T, Fonagy P, Cottrell D, Cotgrove A, Boddington E. Selective serotonin reuptake inhibitors in childhood depression: systematic review of published versus unpublished data. Lancet 2004; 363: 1341-5.

92 Montes JM, Maurino J, de Dios C, Medina E. Suboptimal treatment adherence in bipolar disorder: impact on clinical outcomes and functioning. Patient Prefer Adherence 2013; 7: 89-94.

John H. M. Crichton

A variety of Greek terminology used in tragic drama is translated simply as 'madness': anoia is absence of nous (mental reasoning); paranoia, a sidestep away from nous; paraphron, movement away from phren (the mind); oistros, a fly that bites cows (irritating and persistent) and might refer to an unrelenting passion; Iussa, a violent rage closely associated with wolves. Most commonly mania was used, a term related to menos - a violent force, perhaps originally meaning 'blood'. The terminology of the theatre has proved an enduring influence on psychiatric nomenclature, in contrast to ancient Greek clinical diagnoses such as melancholia and hysteria. 